\title{
Creatividad y conflictos en sociedades contemporáneas. Las artes inclusivas en estrategias de construcción
}

\section{Creativity and Conflict in Contemporary Societies. Inclusive Arts in Construction Strategies}

\author{
Manuel Muñoz Bellerin ${ }^{1}$ \\ ORCID: https://orcid.org/0000-0003-0980-6847 \\ Nuria Cordero Ramos ${ }^{2}$ \\ ORCID: https://orcid.org/0000-0002-9875-1042 \\ Universidad Pablo de Olavide (España)
}

Recibido: 30-04-2021

Aceptado: 30-08-2021

\begin{abstract}
${ }^{1}$ (mfmunbel@upo.es) Profesor Asociado del Departamento de Trabajo Social y miembro del Grupo de Investigación Social y Acción Participativa-GISAP en Universidad Pablo de Olavide. Doctorado en Ciencias Sociales, en la línea de "Cultura, Desarrollo e Intervención Social”. Ha sido Director Académico y docente del Curso de Especialización Universitaria “Teatro Social e Intervención Socio-educativa” (20082013). Actualmente realiza un Proyecto de Posdoctorado sobre Creación Colectiva teatral, Corporalidades y Epistemología del Sur en Centro de Estudios Sociales (CES) de la Universidad de Coimbra. Artículos más destacados: "Social work and applied theatre: creative experiences with a group of homeless people in the city of Seville". European Journal of Social Work (2019); "Etnografía y Creación Colectiva Teatral. Una década de artivismo con personas sin hogar en Sevilla". Arte, Individuo Y Sociedad; "The Role of Applied Theatre in Social Work: Creative Interventions with Homeless Individuals". The British Journal of Social Work (2020); "El cuerpo en la producción de conocimiento: Investigación aplicada en grupos de estudiantes universitarios de Perú y Ecuador. Revista del Laboratorio Iberoamericano para el Estudio Sociohistórico de las Sexualidades (2021); "Citizen Art and Human Rights: Collective Theatre Creation as a Way of Combatting Exclusion". Social Inclusion (2021).

2 (ncorram@upo.es) Profesora Titular del Departamento de Trabajo Social, Doctora en Derechos humanos y miembro de GISAP (Grupo de Investigación Social y Acción Participativa), pertenece a la Red LIESS (Laboratorio Iberoamericano para el Estudio Socio histórico de las Sexualidades) y es miembro permanente del Seminario Antagónicos (Universidad de Sevilla). Entre los artículos especializados se pueden destacar: "The Role of Applied Theatre in Social Work: Creative Interventions with Homeless Individuals" (2020); "Social work and applied theatre: creative experiences with a group of homeless people in the city of Seville" (2019); "Etnografía y Creación Colectiva Teatral. Una década de "artivismo" con personas sin hogar en Sevilla" (2019); "Teatro, Empoderamiento y Capacidades. El teatro como herramienta de la acción social desde la ética de la representación. Caso práctico con grupos de personas en contexto de exclusión en la ciudad de Sevilla" (2019) y La creación colectiva teatral. Método de acción social y resistencia con el colectivo de personas sin hogar en Sevilla, España (2017)".
\end{abstract}




\title{
Resumen
}

En las sociedades actuales existen conflictos que originan una violencia directa en una parte considerable de la ciudadanía. El sinhogarismo es un ejemplo del encubrimiento de una paz social que no es real en cuanto que afecta a quienes no tienen las mínimas garantías socioeconómicas para vivir con dignidad. En este artículo, los autores hacen una reflexión sobre algunas cuestiones relacionadas con este tipo de problemas que permanecen ahogando una auténtica participación $\mathrm{y}$, por ende, la posibilidad de una convivencia democrática más real. Una propuesta de afrontar este tipo de contextos es el arte enfocado como espacio de participación a partir de las experiencias de los participantes. En este caso de aquellos que no tienen las mismas oportunidades de contar cómo sienten lo que les acontece. Concretamente, se expone la metodología del teatro mediando una realidad desde la representación de los cuerpos en calidad de creatividad generadora de interpretaciones diversas y diferentes.

Palabras-clave: creatividad, teatro, conflictos, sociedad.

\begin{abstract}
In today's societies, there are conflicts that cause direct violence in a considerable part of the population. Homelessness is an example of the concealment of a social peace that is not real insofar as it affects those who do not have the minimum socio-economic guarantees to live with dignity. In this article, the authors reflect on some of the issues related to this type of problems that continue to stifle genuine participation and, therefore, the possibility of a more real democratic coexistence. One proposal for tackling this type of context is art focused as a space for participation based on the experiences of the participants. In this case, of those who do not have the same opportunities to tell how they feel about what is happening to them. Specifically, the methodology of theatre is presented, mediating a reality from the representation of bodies as creativity that generates diverse and different interpretations.
\end{abstract}

Keywords: creativity, theatre, conflict, society.

\section{El valor de la creatividad}

El panorama actual no invita a ser optimistas respecto al destino tomado por la especie humana. ¿Es razonable que en pleno siglo XXI siga habiendo hambre, pobreza, guerras? La deducible inteligencia del homo sapiens sapiens, ¿tiene como destino el Leviatán hobbesiano? O, por el contrario, ¿aún cabe la 
esperanza de un horizonte de dignidad para todas y todos? En 1947, tras las tragedias del holocausto y la bomba atómica, Antonin Artaud declaraba:

Aún no hemos nacido.

Aún no estamos en el mundo.

Aún no hay mundo.

Aún las cosas no están hechas.

La razón de ser no ha sido encontrada (2000:7).

En este manifiesto, el autor intentaba advertir de la exigüidad moral del mundo occidental. Una civilización que se encontraba en la zona cero histórica de su tiempo. Al mismo tiempo, sugería la ruptura y una nueva búsqueda a través de la acción re-vivificadora. De una acción que "designa la capacidad de hacer que ocurran acontecimientos en el entorno físico y social del sujeto actuante" (Ricouer 2005: 107). La búsqueda de Artaud pasa por el presentismo de un tiempo redimido en el que hacen acto de presencia los cuerpos olvidados de quienes no fueron. Se trata de un otro- tiempo para "la revelación del quien" (Arendt 2019: 210), para el encarnamiento de las "diversas figuras de todos los tiempos" (Benjamin 2008: 37). Estas figuras son hombres y mujeres que desde un tiempo pretérito hasta el presente transitan en los márgenes de la normalidad pre-establecida. Mujeres y hombres que no están identificadas bajo los arquetipos positivos del modelo cultural racionalista.

Las personas con diversidad funcional y las mujeres sin hogar, los supernumerarios y las inmigrantes forman parte de un lugar y un tiempo sólo reconocible en el mapa humano de las diferencias. Pero, ¿diferentes de qué y de quienes? Desde la mirada reguladora de la unicidad social son diferentes porque no pueden alcanzar el nivel de existencia de los normales. Están fuera del orden natural de las cosas establecidas por la sociedad unidimensional (Marcuse 2016). Desde una mirada inclusiva, la diferenciación potencia la creatividad humana plural como "una fuerza de cambio social" (Mould 2019: 60). Los conocimientos de la otredad, diferentes a los de la racionalidad hegemónica, componen un saber añadido en el proceso de aprendizaje que nos queda por emprender. Las vivencias de personas refugiadas pueden servirnos para comprender mejor la necesidad de desestructurar la violencia de nuestras vidas. Las experiencias de personas ciegas pueden hacernos sentir otras percepciones y otras emociones.

En los años 70, Joseph Beuys (2006) plantea la consubstancialidad de lo artístico como un elemento universal. Con la propuesta de cada hombre, un artista, la actividad creadora adquiere una dimensión que supera la jerarquización establecida por la élite artístico-intelectual y se dirige a una democracia cultural. En este modelo de cultura, la creatividad se erige en un motivo de auténtica participación y de ciudadanía, sin distinciones peyorativas. Como 
argumenta Galtung, "la mejor forma de construir creatividad es practicándola: se construye capacidad ciudadana" (1998:113). Rechazamos lo creativo impuesto en la posmodernidad y que esta dirigido a "lo que produce valor o a lo que alimenta la reproducción ampliada del capital” (Pelbart 2009: 95). Es una creatividad que se dirige a la búsqueda de otras formas de comprender y activar el mundo. Desde este prisma, ejercer la creatividad significa poder conocer los imaginarios que cada uno de nosotros albergamos. También, revelar los miedos y los deseos, las frustraciones y los sueños. Trasladado al espacio compartido de las interacciones, es un modo de intercambio en el que cada cual se nuestra tal como es. Es un mostrarse que puede enseñarnos modos relacionales distintivos de cómo somos y reaccionamos ante las cosas. Y, en paralelo, puede abrirnos hacia otras formas de relaciones donde tiene más sentido la dignidad y el respeto por la vida. En definitiva, de entendernos como un paso ineludible en el complejo proceso de reconstruirnos en paz.

En las sociedades de nuestras ciudades laten conflictos liberados en una tierra de nadie. Parecen dilemas velados tras una moral escrupulosa de sus vergüenzas. Conflictos invisibles para las conciencias líquidas de esta era moderna (Bauman 2013). Están tan presentes en la cotidianeidad de la vida que resultan naturales. Algunos de ellos, por ejemplo la precariedad laboral o la falta de una vivienda, son tildados de problemas estructurales. En ocasiones, son considerados fenómenos que están ahí: transcurren entre la indiferencia y el desagrado. La inmigración, la trata de seres humanos o el sinhogarismo no suelen ser temas personales: son asuntos que les suceden a los demás. Sin embargo, para las personas que padecen este tipo de cosas, pueden convertirse en incidentes que condicionan sus vidas de manera determinante. Incidentes que pueden originar la estigmatización, la violencia, la muerte, etc. De ahí que llevar al plano de los conflictos este tipo de hechos es hacerlos visibles para así analizarlos y afrontarlos. Al mismo tiempo, es una manera de des-estigmatizar un problema que vulnera la dignidad de las personas afectadas, situándolo justamente en el terreno de la responsabilidad política de los gobiernos y las instituciones públicas (Ignatieff 2018).

\section{La irracionalidad del sinhogarismo. Ejemplo de un conflicto en sociedades contemporáneas}

El sinhogarismo es un ejemplo vigente de la vulneración de derechos. Conceptos como sin hogar o sin techo encubren una nueva variante de atribución social en negativo dirigida a quienes no tienen las mínimas garantías socioeconómicas para vivir con dignidad ${ }^{3}$. Son arquetipos de una continuidad

3 Sinhogarismo es empleado para connotar la pérdida de un hogar. Por su parte, el término sin 
histórica que deviene de otras figuras alegóricas relacionadas con la división del ser y el hacer humanos que confluyen en fenómenos como la exclusión. Exclusión en cuanto al "resultado de un grave proceso de desigualdad en la satisfacción de las necesidades humanas, especialmente en la distribución de la renta y la participación social" (Cabrera Cabrera 2002: 16).

Al pauperismo del siglo XIX y la cuestión social de principios del XX como formas históricas programadas por el capitalismo, le sigue la crisis generada por las políticas neoliberales que condujeron a la desindustrialización y el desempleo. El problema de la vivienda es uno de los últimos eslabones de esta misma dinámica. La nueva realidad social impuesta por el virus del Covid-19 ahonda más en este agravio comparativo de las divergencias sociales ${ }^{4}$. Si la crisis sobrevenida desde 2008 acrecentó el número de personas en situación de sinhogarismo, el confinamiento ha acentuado aún más la bolsa de la desigualdad con una mayor incorporación de jóvenes y mujeres ${ }^{5}$.

Las biografías de protagonistas recogidas por Tejero Gil y Torrabadella García (2010) y por Mayock \& Sheridan (2016) reflejan el desasosiego que es vivir sin un techo ni un hogar. Al deterioro de la identidad generado por la estigmatización (Goffman 2010) se une el sentimiento de vergüenza por no cumplir con los roles asignados por un sistema social que basa el éxito, precisamente, en aquello que no tienen: un hogar, un empleo, una red sociofamiliar estable, etc. No obstante, el conflicto subyacente no es meramente de carácter socio-económico. No es sólo la falta de un empleo y una vivienda, es un problema que tiene que ver, también, con las soledades, miedos y sufrimientos. Para muchas personas que padecen esta situación, no disponer de una residencia donde habitar, donde construir-se como ser humano y tener que alejarse de su territorio más íntimo y próximo, es decir, su hogar, supone un auténtico conflicto. Más aún se les descontextualiza de su propio contexto social y se les reubica en otro totalmente ajeno: centros de acogida, centros institucionales de diferente tipo, etc. En cuanto a las mujeres, la causa principal por la que salen del hogar es debido a la violencia y el abuso doméstico, experimentando una mayor tasa de marginalidad socioeconómica que los hombres (Bretherton 2017). La doble discriminación que sufren muchas mujeres sin hogar (por ser mujer y por no tener un hogar) genera una mayor dificultad en el acceso a la igualdad.

La cuestión que se plantea es si el sinhogarismo responde manifiestamente a un conflicto. Si nos atenemos a la explicación dada por Galtung (1998) sobre

techo alude a personas que no tienen una vivienda digna y habitan en lugares públicos, bien sea en las calles de las ciudades o en dispositivos de acogimiento dispuestos por los servicios sociales y otras instituciones.

${ }^{4}$ El País, "Los techos derribados por la pandemia". https://elpais.com/sociedad/2020-12-14/lostechos-derribados-por-la-pandemia.html

5 RTVE, https:www.rtve.es/noticias/20201114/sin-hogar-segunda-ola-frio-confinamiento/2054469.shtml

Araucaria. Revista Iberoamericana de Filosofía, Política, Humanidades y Relaciones Internacionales, año $23, \mathrm{n}^{\circ} 48$. Tercer cuatrimestre de 2021. Pp. 401-416. ISSN 1575-6823 e-ISSN 2340-2199 https://dx.doi.org/10.12795/araucaria.2021.i48.18 
la violencia estructura y cultural, efectos como la privación de una vivienda, la falta de empleo y la desvinculación forman parte de un conflicto que afecta de manera directa a la mente, el cuerpo y el espíritu de las personas. La violencia cultural dirigida a las personas afectadas por el sinhogarismo está prescrita por la culpabilización: son ellos y ellas los responsables de la situación. La autoculpabilidad marca doblemente la identidad de la persona. De una parte, asume un concepto negativo de sí mismo aquejando su personalidad. Anímicamente le constriñe la apatía y falta de voluntad frente a unos cambios inesperados y mucho menos deseados. A la salud mental y anímica (espíritu) se une, si la estancia en la calle ha sido prolongada, los efectos físicos definidos con marcas en el cuerpo debido a una vida insalubre. Con el concepto de imperialismo cultural, Young relaciona este tipo de violencia con la opresión que unos grupos ejercen sobre otros que "consiste en hacer que un grupo sea invisible al mismo tiempo que resulta marcado y estereotipado. Los grupos culturalmente imperialistas proyectan sus propios valores, experiencias y perspectivas con carácter normativo y universal" (2000: 208). Por medio de estereotipos y prejuicios, la narrativa cultural hegemónica aplicada en este contexto tiene como finalidad dotar de coherencia una situación de discriminación, opresión (según Young) y/o desigualdad, justificada por el sistema social imperante.

Ya se ha comentado anteriormente, la falta de bienes y recursos para la sustentación de una vida digan está arraigado a una estructura social de desigualdad. Que existan ciudadanos y ciudadanas que no tienen las necesidades básicas cubiertas para tener un nivel de bienestar idóneo frente a otros que si las tienen es motivo para considerar que el sistema social encubre dicha desigualdad. Estamos de acuerdo con Lederach cuando señala "la necesidad de situar cualquier conflicto dado en un marco temporal expansivo" (1998: 91). El problema del sinhogarismo viene latiendo en las sociedades desde hace décadas bajo la coartada de las políticas de ajuste y reajustes económicos. Por tanto, no es un acontecimiento puntual. Tampoco depende directamente de las crisis intermitentes. Es un conflicto provocado por el capitalismo en un contexto socio-histórico donde no se han superado niveles de discriminación en el mundo. La conexión con la violencia estructural es porque acarrea dominación y opresión, en cuya combinación se produce "el fenómeno conocido como exclusión (social) o marginación” (Galtung 1998:71). Para Young dominación y opresión constituyen los dos ejes principales de la desigualdad estructural contra una parte importante de la ciudadanía.

La dominación consiste en la presencia de condiciones institucionales que impiden a la gente participar en la determinación de sus acciones o de las condiciones de sus acciones[...] La opresión consiste en procesos institucionales sistemáticos que impiden a alguna gente a aprender y usar habilidades satisfactorias y expansivas en medios socialmente reconocidos, o 
procesos sociales institucionalizados que anulan la capacidad de las personas para interactuar y comunicarse con otras o para expresar sus pensamientos y perspectivas sobre la vida social en contextos donde otras personas pueden escucharlas (2000:98)

No obstante, el sinhogarismo no es abarcable exclusivamente desde la dimensión macro-estructural. Se trata de una crisis de valores fundamentales en nuestro mundo contemporáneo (Cortina Orts 2017) que requiere del componente socio-afectivo en toda su extensión y diversificación. De ahí, el riesgo de hablar del sinhogarismo como un ente neutro y despersonalizado. Las personas en situación de sinhogarismo son seres humanos, cada uno con una historia y una textura que los hace inigualables entre sí. El sinhogarismo es de por sí una imposición para la mayoría: una imposición a una vida no deseada ni escogida. Para un número considerable de la ciudadanía, no hay opciones a una vida digna, no existen las oportunidades para decidir sobre sus vidas. Esto tiene efectos directos en el nivel de auténtica participación política, social y/o cultural. Una vez en la calle, las oportunidades para desarrollarse como personas se limitan a un estado de supervivencia. A esto se le une que no existen espacio ni dispositivos donde establecer un nivel de comunicación y participación saludables. Pero, sobre todo, tiene consecuencias graves en la salud física y psíquica. La negación a la libertad sobre sus vidas deja en evidencia cualquier otro tipo de libertad en entornos democráticos.

\section{La filosofía de la creatividad y la actividad inclusiva del arte}

Enfocar una filosofía de la creatividad tiene la finalidad de orientarnos hacia un modelo social pacífico, desde la dignidad y la igualdad. Es una filosofía abierta a la sinergia entre disciplinas que entran en contacto con objeto de dilucidar un saber diferente. Un saber construido por personas y experiencias, procesos y acciones. Quizá, más que de una filosofía, sea más adecuado hablar de una transfilosofía. Un modo de pensar el mundo y organizar las maneras de vivir a través de puentes y cruces que nos lleven a otros tránsitos. Encuentros donde configurarnos como seres en armonía con el entorno ecológico y humano del que formamos parte. Como afirma Nicolescu el prefijo trans indica "lo que está a la vez entre las disciplinas, a través de las diferentes disciplinas y más allá de toda disciplina. Su finalidad es la comprehensión del mundo presente en el cual uno de los imperativos es la unidad del conocimiento" (2014:35).

Más que de unidad, el conocimiento interdisciplinario surge de afrontar la diversidad. Del encuentro con la pluralidad de saberes procedentes de diferentes espacios, personas y experiencias. Con objeto de ampliar el espectro creativo, es un conocimiento abierto a la experimentación de diferentes disciplinas y 
culturas con el objetivo de posibilitar nuevas relaciones sociales. La cuestión está en cómo desarrollar espacios donde llevar a cabo este tipo de experiencias. Nuestra propuesta es la actividad artística enfocada a un proceso basado exclusivamente en la producción inmaterial que las personas experimentan y crean a partir de un estado de ánimo, un cambio de actitud o una emoción. La creatividad artística ofrece la oportunidad de expresar sentimientos, emociones, experiencias: es un espacio de libertad para poder decir, poder contar y contarse a sí mismo, para poder hacer (Ricoeur 2005). Al igual que el arte, la creatividad es política (Mould 2019). Y como tal no es neutral: cumple la función de problematizar la historia a través de una revelación.

La fenomenología del arte como actividad trasciende la realidad y se encamina a la libertad gracias a la imaginación que según Carlos Fuentes "convierte la experiencia en destino para salvar el destino de la simple fatalidad" (2001). En el mundo actual, donde muchos seres humanos sufren la fatalidad atravesada del miedo, la discriminación o el odio. Donde aún no están aseguradas las necesidades básicas para todas y todos: aún tenemos el arte como reducto de libertad. La posibilidad de que las artes puedan superar la distopía a la que nos quiere abocar el sistema hegemónico actual requiere de una orientación transformadora que en términos de conflictos supone "ayudar a transformar a los individuos comprometidos" (Baruch Bush y Folger 2006: 131). En nuestro caso, hablamos de transformación cuando se produce un cambio cualitativo generado en los seres humanos a partir de una experiencia vivida que les permite reorganizar uno o algunos aspectos de su existencia. Dicha reorganización está impulsada por la relación entre personas a partir de la experiencia artística. La danza, el teatro o la música son formas de apropiación de una realidad en conflicto para quienes necesitan afrontarla de manera crítica. Este afrontamiento permite una toma de conciencia que posibilita identificar la opresión, la violencia o la desigualdad en sus múltiples y diferentes manifestaciones con objeto de idear otras alternativas.

Uno de los dispositivos de apropiación y confrontación de los problemas son las experiencias. En el caso del arte, Dewey (2008) reconoce que la experiencia estética del arte conecta al ser humano con lo social a través de una actividad que permite darle sentido a las cosas de la vida. El director de cine ruso Andrei Tarkovski señala que el "arte simboliza el sentido de nuestra experiencia” (2019: 215). La urdimbre de coligar la estética artística y la experiencia humana en el tratamiento de conflictos está en el testimonio simbólico acerca de cuando, cómo y por qué sucedieron. Así como de buscar cómo resolver dichos conflictos de manera positiva. Para ello, es necesario que las artes sean dispositivos de auténtica participación. Articular acciones donde sea viable tratar los conflictos sociales de manera prioritaria y constructiva. Enfocar los conflictos generados por las políticas sociales, la economía o 
las crisis como oportunidades de crecimiento social es un reto permisible si conferimos de autoridad a los y las protagonistas. Desde este prisma, decimos que las artes se dirigen a la búsqueda de un espacio propio donde se activan estrategias de comprensión de las cosas que pasan en la vida.

La función participativa- constructiva de la creatividad artística en los conflictos sociales es el tema central de este trabajo. Este enfoque se fundamenta en dos áreas complementarias: de un lado, en el reconocimiento de las distintas formas de seres humanos que somos dónde cada cual pueda realizarse en la "plena garantía de su identidad" (Ricoeur 2005: 256). Este reconocimiento no trata de señalar unívocamente las distinciones entre unos y otros, sino que establece un diálogo para la comprensión e identificación de las diferencias. Complementariamente, la actividad artística promovida en la danza, el teatro o la performance es constitutiva de una acción específicamente programada y sistematizada. Una actividad que por medio de la experiencia estética nos sensibiliza en la reciprocidad simétrica a través de relaciones fundamentadas en el respeto y la horizontalidad. La acción ética del arte se convierte en un proyecto de inclusión social cuando está apoyada en este tipo de reciprocidad. La creatividad es una disciplina, se experimenta por medio del cuerpo y la palabra. Uno de sus cometidos es que las personas puedan contar acerca de la realidad compleja que les acontece a través del acto comunicativo. Pero, es bastante probable que este acto sea nuevo, que no sea un hábito del que fijarse. De ahí que sea necesario encontrar la imaginación moral que se lleva a cabo en el proceso artístico comunicacional e interactivo entre los sujetos y que otorga un tipo de dialéctica que "surge de la experiencia humana y después da forma, expresión y significado a esa experiencia. La construcción de la paz tiene esa misma cualidad artística. Debe experimentar, imaginar y dar a luz la red de relaciones (Lederach 2007: 70).

Para comunidades y grupos en situación de exclusión, opresión o dominación, como es el caso del sinhogarismo, el acceso a un discurso propio está sometido a las oportunidades que el sistema sociopolítico les otorgue de tomar la palabra y la acción. De ahí que el carácter inclusivo de las artes esté mediado por la capacidad de restituir a las personas la dignidad para que sean autónomas, para que decidan por sí mismas. En manifestaciones artísticas como el teatro, palabra y acción son herramientas de un proceso cultural que potencia lo instituyente frente a lo instituido. Tomando como referencia la tesis de Castoriadis (2013), y trasladada al terreno de la praxis artística, lo constituido consiste en lo previamente organizado por una institución que cree saber las necesidades e intereses de las personas pero que no cuenta con la opinión y participación de estas. Es un modo adaptativo a las circunstancias ofrecido por el sistema de comunicación funcional con la finalidad de "enseñarnos a olvidar: a traducir lo negativo en positivo" (Marcuse 2016: 130). Por el contrario, lo 
instituyente consiste en un proceso que cuida los contextos sociales y culturales, que tiene en cuenta los tiempos y los espacios de las personas. Es instituyente porque se está haciendo en base a consensos, se tiene en cuenta las historias y los relatos de las personas. Esta segunda opción es posible trabajando juntos en la praxis de una democracia cultural activadora de un discurso y una acción que emerge de los y las protagonistas.

\section{La actividad artística del teatro en enfoques de orientación transformadora de los conflictos}

En este apartado se comparte un modelo práctico basado en el teatro como metodología que asume los conflictos como una forma de construir oportunidades y de aprendizaje social. De las artes, el teatro es la manifestación artística donde las relaciones humanas y la comunicación interpersonal se desarrollan de manera más directa. No es una propuesta metodológica al uso, es una praxis sistematizada a través de experiencias propias y conocimientos aportados por los y las protagonistas de diferentes proyectos, talleres o seminarios en los que hemos podido participar. En definitiva, es un proceso que no está cerrado, prosigue con sus defectos y fortalezas, con muchas contradicciones y alguna que otra certeza. Consta de una idea teórica y de un idea práctica.

La primera gira en torno a la teatralidad como práctica cultural. En el contexto comunicacional, los signos, gestos y actitudes de la teatralidad sirven de códigos tan reveladores como las palabras. A diferencia de la concepción de lo teatral como representación y recepción, la teatralidad gira en torno a la funcionalidad del teatro como acto comunicativo. Es un acto establecido en la teatralidad como escenario ideográfico de representación de las experiencias. Respecto a la oportunidad de crecimiento a partir del conflicto, es el marco de identificación que tenemos en el constante y fluctuante proceso de vincularnos en la búsqueda de otros modelos de relacionarnos y convivir. La teatralidad como práctica cultural es un concepto con el que definimos una tentativa de respuesta a esquemas de dominación y opresión que resultan de los conflictos sociales. Se materializa a través de acciones, imágenes, archivos, etc., que nos permiten descubrirnos y descubrir otros espacios de convivencia desde la expresividad y desde una estética (una expresividad estética) que tiene en cuenta las experiencias históricas de las comunidades y las personas.

La segunda idea aterriza más en lo metodológico. Es una propuesta que trasciende lo artístico para convertirse en una transteatralidad. Sobrepasa los límites de lo espectacular con objeto de buscar estrategias de orientación transformadora junto con las personas. Surge de la transdisciplinariedad. Concretamente de técnicas, dinámicas y ensayos que proceden de las ciencias 
sociales, la mediación y el tratamiento de conflictos y la pedagogía teatral. Se programa en 2 áreas, cada una corresponde a un contexto de demanda/ necesidad dentro del conflicto planteado por los protagonistas o por las instituciones. Ambas áreas pueden ser diseñadas separadamente o unidas dependiendo de los objetivos.

A. Las experiencias narradas en el tratamiento de conflictos

En la práctica cultural del teatro lo anecdótico está conectado a la idea de que son en los actos cotidianos donde encontramos los hechos sociales que señalan relaciones de poder. Estas relaciones están dentro de un conflicto que tiene como efectos la violencia y que ya fueron explicadas en apartados anteriores. Por tanto, los actos cotidianos nos sirven para reflejar ideas dominantes que encuentran significados en estigmas, discriminaciones, etc. Y de otro lado, sirve para ensayar otras prácticas de relacionarnos y actuar de manera diferente. De lo anecdótico y lo experiencial nos interesa el análisis de los hechos cotidianos para debatir acerca de las actitudes inmediatas, de cómo reaccionamos y cuales son las bases de estas actitudes. Pero, hay una segunda dimensión: esos hechos nos llevan a un análisis de las estructuras, aquellas que están subsumidas en lo cultural, en lo socio-político y lo económico. En ocasiones, los hechos sociales enmascaran formas subliminales a penas perceptibles. Las experiencias ofrecen un soporte dialéctico donde las personas relatan secuencialmente o de manera espontánea secuencias, momentos, detalles, etc., que pertenecen a la historia del conflicto. Las técnicas más utilizadas en una primera fase proceden de las ciencias sociales y la mediación- tratamiento de conflictos.

Todas las técnicas de esta área son programadas en su conjunto de manera complementaria. Los microrelatos consisten en la elección y selección por parte del participante de aquellas épocas o fechas de la historia de vida que considera relevantes. Algunas pueden contener relatos directos de conflictos; o, pueden estar dispersos en el relato general de la narración. Si el participante lo estima de utilidad, se puede incorporar la técnica storyboard que consiste en la creación de un dibujo o collage donde simboliza a través de imágenes, fotografías, etc., una secuencia de hechos puntuales o lineal relacionado con el conflicto. Si bien en el microrelato la atención va más enfocada a la subjetividad de cada persona, el grupo de discusión se centra en lo grupal. En estos, el grupo de participantes eligen una situación conflictiva común. La finalidad consiste en poner en diálogo las diversas percepciones de la realidad de los sujetos participantes. Por último, la escultura es una técnica intersubjetiva que se realiza entre dos participantes y en la que cada uno esculpe en el cuerpo del compañero una imagen que simboliza aspectos del conflicto centrados en lo corporal. 


\section{Las experiencias narradas en el tratamiento de conflictos}

\section{Microrelatos}

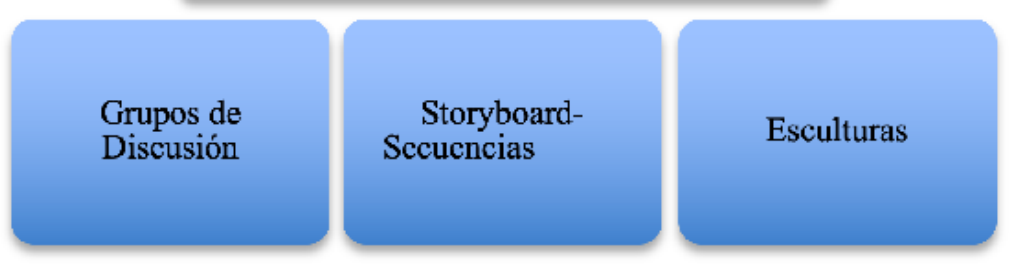

Fuente: Autores

\section{B. La corporeidad creativa en el tratamiento de conflictos}

A través de la creatividad y el imaginario adscritos a la corporalidad como medio de conocimiento (Adorno, 2005), el teatro aporta una nueva dimensión de la comunicación. Al igual que las palabras, el cuerpo también es un medio de información del conflicto. A veces, puede complementar el lenguaje oral; pero, en otras, reproduce de manera eficiente lo que las palabras esconden, o no saben emitir. Cada cuerpo es un ente de expresión creadora y esta diversidad no está regulada por una estética dominada por cánones de belleza según patrones culturales hegemónicos. La narrativa que el cuerpo hace del conflicto contiene una verdad que subyace a la comunicación verbal. Un movimiento, una contorsión, la inmanencia de una imagen realizada por el cuerpo forma parte de lo íntimo, de lo sentido de manera única. Es una comunicación que no puede permanecer escondida por el juego de las palabras. El cuerpo contiene un valor emocional que nos permite expandir la percepción del problema y, con ello, de ampliar los límites de su interpretación. Lederach habla de un valor emocional que "se adentra allá donde está arraigado el significado. Intenta hallar donde reside el significado en la experiencia de la gente" (2007:72). Tomar sentido de lo corporal en el espacio simbólico o real del conflicto le permite a la persona evocar aquellos "lugares habitados" (Ricoeur, 2010:65). Los ejercicios de este área giran en torno a la expresividad de cuerpo. Sin embargo, en muchos casos, hay técnicas como el grupo de discusión que son necesarios y, en cierto modo, se complementan con aquella. 
Teatro imagen y teatro foro son técnicas procedentes del método de teatro del oprimido de Augusto Boal (1989). La primera parte del conflicto y el participante solo puede usar su cuerpo como medio de expresión. A partir de esta pauta, se llevan a cabo tres tipos de imágenes. De la imagen real se pasa a la imagen ideal y de esta a la imagen tránsito. Es decir, desde la pauta de la imagen real del conflicto concebido por el participante se llega a la imagen ideal o deseada para, finalmente, mostrar el cambio que se produce entre estas a partir de la imagen tránsito. Respecto a teatro foro, es una técnica adecuada para tratamiento de conflictos a nivel grupal. A partir de un conflicto dado, una parte del grupo ensaya el problema y la solución. A continuación se representa ante la otra parte del grupo pudiendo éste, al finalizar la primera representación, aportar cambios alterando cada uno de los personajes, así como las acciones y actitudes. Gesto social es una técnica de Bertolt Brecht (2004) adaptada por los autores que consiste en reproducir y analizar aquellas secuencias del conflicto que connotan actitudes negativas en las relaciones sociales y que se derivan de los estatus de poder y opresión. Por último, las improvisaciones personales consisten en el relato personal de un conflicto que es ensayado de manera real o simbólica con objeto de ser representado y analizado por el resto del grupo o ante un público. En esta técnica tiene cabida una amplia gama de recursos expresivos donde cada participante puede elegir qué formas utilizar para realizar su improvisación.

\section{La corporeidad creativa en tratamiento de conflictos}

\section{Improvisaciones personales}

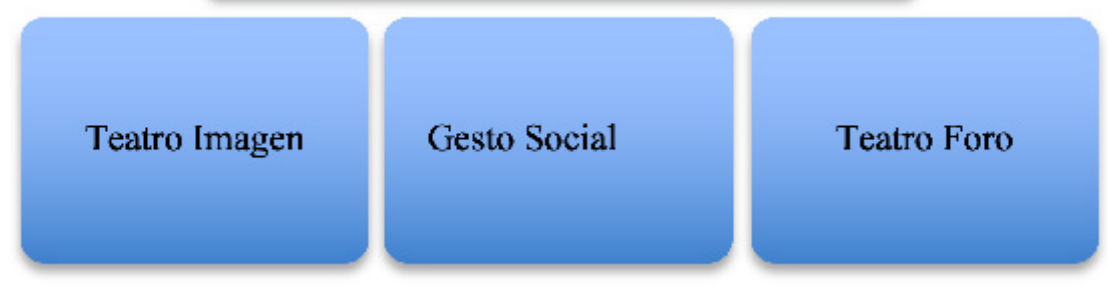

Fuente: Autores 


\section{Conclusiones}

El teatro con enfoque de tratamiento de conflictos se fundamenta en la creatividad humana. Establece conocimientos y aprendizajes encaminados a un tipo de interacciones que valora la búsqueda de espacios sociales donde la convivencia sea posible desde la dignidad y la igualdad. Autores como Baruch Bush y Folger (2006) proponen la revalorización como una fase indispensable para que las partes mas silenciadas y oprimidas en el conflicto puedan recuperar un nivel de autoestima aceptable y así afrontar en equidad una mediación. Tal como se ha venido comprobando en el trabajo realizado con personas sin hogar (Cordero Ramos \& Muñoz Bellerin 2017), la inclusión del teatro facilita que las personas puedan adquirir una perspectiva nueva acerca de los problemas, sus orígenes y sus formaciones; pero, sobre todo, permitiendo liberar a las personas de culpabilidades y llevando el proceso a nuevas interpretaciones. Desde una concepción transdisciplinaria y dialéctica, el arte desarrolla alternativas de crecimiento a través de la reconciliación y la reconstrucción de otros modos convivenciales.

La representatividad de la corporalidad creativa sirve a modo de narrativa de una re-historización de los conflictos sociales que antes quedaban invisibles. De esta manera se está dando lugar a democratizar sociedades donde conflictos como el sinhogarismo constituyen una quiebra de derechos humanos. Esta representatividad está configurada por espacios, tiempos, son lenguajes de participación activa para aquellos/as que no están representados en el marco político, social o cultural. El arte como forma de narratividad a partir de las experiencias humanas de individuos y colectivos que no están representados por el sistema cultural hegemónico es un arte con un canon que no es exclusivo de los modelos dominantes. Se proyecta en una estética del encuentro, de modelos relacionales en igualdad, donde situar la vida y el mundo a partir de las visiones acordadas por los grupos y las personas.

En definitiva, las artes se convierten en procesos transformativos dentro de la sociedad cuando se convierte en un medio para que personas y grupos recuperen la comunicación acerca de sus problemas. Problemas que, en numerosas ocasiones, fueron originados de manera directa por las políticas socioeconómicas de los gobiernos. La función principal del teatro en el tratamiento de los conflictos sociales es la de posibilitar que la gente hable, se exprese y tome decisiones sobre problemas que le conciernen y que les causa una violencia directa. Brecht dijo que "la realidad ha de estar transmitida por el arte para que se reconozca y se trate como algo que puede ser cambiado" (2004: 31). Para sociedades con conflictos internos que causan desigualdades, discriminación, etc., la realidad no puede ser obviada: debe afrontarse de manera constructiva. Por ello, las tácticas transformativas de los proyectos 
artísticos tienen que servir de alternativas que nos permitan cambiar las lógicas de dominación reflejadas en la cotidianeidad de un hogar, de un grupo social, de una institución o de una comunidad. La experiencia del arte mediador complementa la tarea del teatro como herramienta de interpretación y, sobre todo, de identificación y tratamiento de esas cotidianeidades que forman parte de una otredad desconocida, oculta, aquella que está en las sombras de la exclusión.

\section{Bibliografía}

Adorno, T.: Dialéctica Negativa. La jerga de la autenticidad, Madrid, Akal, 2005.

Arendt, H.: La condición humana, Barcelona, Paidós, 2019.

Artaud, A.: Textos, Barcelona, Plaza \& Janés, 2000.

Baruch Bush, R.A. y Folger, J.P.: La promesa de mediación. Cómo afrontar el conflicto a través del fortalecimiento propio y del reconocimiento de los otros, Barcelona: Granica, 2006.

Bauman, Z.: Vida líquida, Barcelona, Planeta, 2013.

Benjamin, W.: Tesis sobre la historia y otros fragmentos, México, Universidad Autónoma, 2008.

Beuys; J.: Ensayos y entrevistas, Madrid, Síntesis, 2006.

Boal, A.: Teatro del oprimido, México, Nueva Imagen, 1989.

Boal, A.: La estética del oprimido, Barcelona, Alba, 2012.

Brecht, B.: Escrito sobre teatro, Barcelona, Editorial Alba, 2004.

Bretherton, J.: Reconsidering gender in homelessness, European Journal of Homelessness, Volume, 11(1), 2017

Cabrera Cabrera, P.J. (Dir.), Malgesini, G. y López Ruíz, J.A.: Un techo y un futuro. Buenas prácticas de intervención social con personas sin hogar, Barcelona, Icaria, 2002.

Castoriadis, C.: La institución imaginaria de la sociedad, Barcelona: Tusquets, 2013.

Cortina Orts, A.: Aporofobia. El rechazo al pobre. Un desafio para la sociedad democrática, Barcelona, Paidós, 2017.

Fuentes, C., Cátedra Alfonso Reyes, 29 de marzo de 2001, La escritura: encuentro y memoria, conferencia, 29 de marzo de 2001, https://youtu.be/ ywzlcdzOCnY

Galtung, J.: Tras la violencia, 3R: reconstrucción, reconciliación, resolución. Afrontando los efectos visibles e invisibles de la guerra y la violencia, Bilbao, Gernika Gogoratuz, 1998. 
Goffman, E.: Internados. Ensayos sobre la situación social de los enfermos mentales, Buenos Aíres, Amorrortu, 2008.

Ignatieff, M: Las virtudes cotidianas. El orden moral en un mundo dividido, Barcelona, Taurus, 2018.

Marcuse, H.: El hombre unidimensional, Barcelona, Austral, 2016

Mayock, Paula \& Sheridan, Sarah. (2016). Women and long-term homelessness. The Magazine of FEANTSA (European Federation of National Organisation Working with the Homeless), pp. 4-7. Recuperado de https:// www.feantsa.org/.../summer-2016-perspectives-on-women

Mould, O.: Contra la creatividad. Capitalismo y domesticación del talento, Madrid, Alfabeto Editorial, 2019.

Cordero Ramos, N. \& Muñoz Bellerin, M., Social work and applied theatre: creative experiences with a group of homeless people in the city of Seville, European Journal of Social Work, 2017, DOI: 10.1080/13691457.2017.1366298

Nicolescu, B.: Methodology of transdisciplinarity. World futures, The Journal of new paradigam research, 2014, Recuperado de https://doi:10.1080/026 04027.2014.934631

Pelbart, P.P.: Filosofía de la deserción: nihilismo, locura y comunidad, Buenos Aires, Tinta Limón, 2009.

Ricoeur, P.: Caminos del Reconocimiento. Madrid, Editorial Trotta, 2005.

Ricoeur, P.: La memoria, la historia, el olvido, Madrid, Editorial Trotta, 2010.

Tarkovski, A.: Esculpir en el tiempo, Madrid, Ediciones Rialp, 2019.

Tejero Gil, E. y Torrabadella García, L.: Vidas al descubierto. Historias de vida de los "sin techo", Barcelona, Icaria, 2010.

Young, I. M.: La justicia y la política de la diferencia, Valencia, Cátedra, 2000. 